\title{
Review on the Evaluation of Casing Damage Level in Oil and Gas Field
}

\author{
Fangcheng Zhou ${ }^{1}$, Tao $\mathrm{Wang}^{2}$, Changqing $\mathrm{Ma}^{2}$,Pengfei $\mathrm{Lei}^{2}$,Xinyi Zhang ${ }^{1}$ and Qingxin $\mathrm{Ding}^{1}$ \\ ${ }^{1}$ China University of Petroleum (Beijing), College of mechanical and storage engineering, 102200, Beijing, China \\ ${ }^{2}$ Engineering Technology Research Institute of Huabei Oilfield Company, 062500, Hebei, China
}

\begin{abstract}
The casing damage is a common problem encountered in the oil and gas field, and the casing damage will cause huge losses to the economic benefits of the oil and gas field. Grading the damage degree of the casing damage well can provide theoretical support for the oilfield workover operation and save the cost of workover. The casing damage classification has a strong guiding significance for the economic evaluation of the casing damage repair and the development of appropriate workover technology. After a review research on domestic and foreigner papers on the study of casing damage classification, it can be found that there is no mature theory and method for casing damage classification. After analyzing the entire workover process, the concept of the damage repair evaluation expert system is proposed to complete the entire workover process, evaluate the cost, and help the oil and gas field to obtain the best benefits.
\end{abstract}

\section{Detection and identification of casing damage wells}

During the production cycle, oil and gas wells will cause some damage to the downhole casing due to factors such as the movement of the formation and the corrosion of oil and gas [1]. Serious damage can lead to the retirement of oil and gas wells, causing irreparable economic losses to the oil fields [2]. The data of oil and water well casing damage in Huabei Oilfield has been counted for nearly 30 years, and the number of casing damage in oil and water wells has reached more than 1700. Among them, the deformation of the casing accounts for more than $75 \%$, and the depth of the well in the casing damage is mostly more than 1000 meters. The specific casing damage distribution is shown in Figure 1.

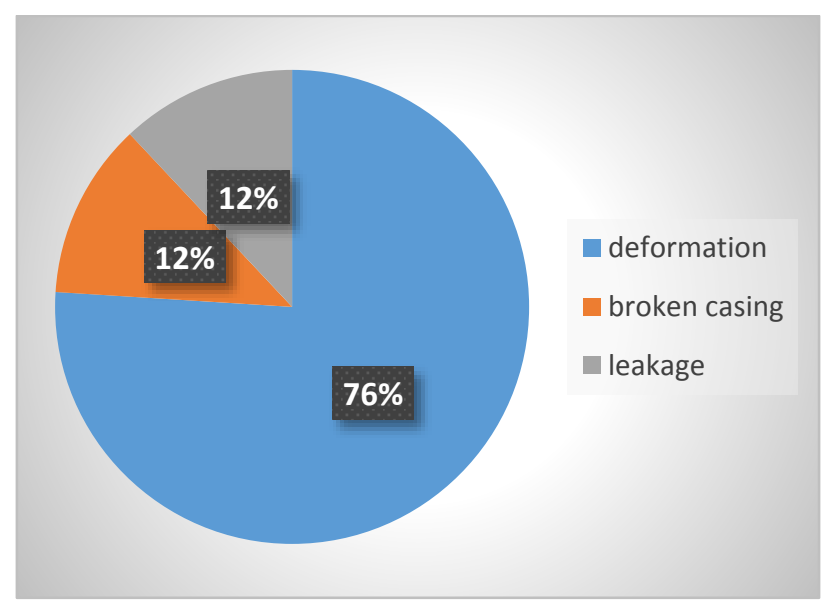

Fig. 1. Proportion of casing damage in oil and water wells in Huabei Oilfield.
When casing damage is found in the production cycle of an oil field, it is necessary to perform well-shut-in and flaw detection. The detection of casing damage in oil and gas wells is inseparable from the caliper. The data fed back through the Multi-arm caliper is the most effective way to detect casing damage [3]. The ability of caliper flaw detection and the processing of caliper monitoring data in the later period have great influence on the identification of casing damage degree and the formulation of workover technology [4]. In recent years, scholars have made a lot of efforts in the exploration of caliper test data.

Taking the 16 arms caliper for example, the 16 arms of the 16-arm caliper are evenly distributed on a circle, and each arm is equipped with a sensor, which is controlled by a regulated power supply. When the caliper travels within the range to be measured, a linear relationship between the caliper and the output voltage can be ensured. Huabei Oilfield conducts casing damage detection on Jing 22-19 well through the hexapod instrument caliper, and processes the caliper data to generate a two-dimensional map, as shown in Figure 2. According to the image, severe bending occurred at a depth of 1994-2019 meters. 


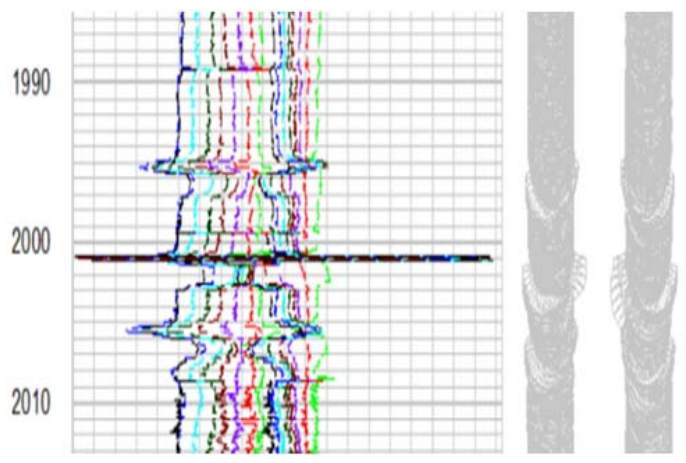

Fig. 2. Two-dimensional diagram of 16-arm caliper damage detection.

Liu Ling of Northeast Petroleum University and Qi Wenjuan of Xi'an University of Science and Technology have studied the 3D imaging technology of caliper in their master's theses [5-6]. Qi Wenjuan designed a 3D imaging system based on the general 3D image standard OPENGL in her master's thesis "The Research and Implementation of 3D Imaging System for Multi-arm caliper logging tool". The system can display the 3D display of the data detected by the caliper. On the display, with rotation, zoom and other functions. It has a strong guiding significance for the identification and maintenance of casing damage. The 3D imaging of the casing damage section is shown in Figure 3.

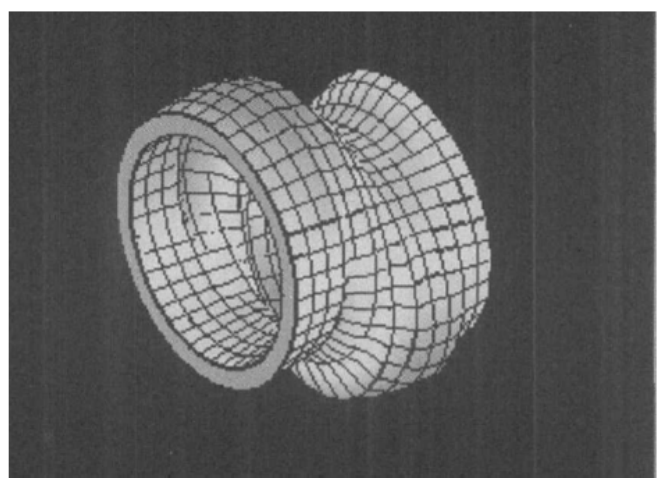

Fig. 3. Three-dimensional imaging of the loss section [6].

Zhang Nana of Xi'an Petroleum University compared the advantages of mechanical caliper detection, ultrasonic caliper detection and electromagnetic caliper detection technology in her master's thesis "Research on Casing Damage Multi-arm Caliper Detection Technology" [7]. A set of electromagnetic casing damage detection system was designed and tested in the laboratory environment. It is a direction for the development of caliper inspection.
Xiao Yong of Daqing Petroleum Institute, Jia Jianghong of China University of Petroleum (East China) and others studied the occurrence of predicted casing damage according to the mechanism of casing damage [8]. Jia Jianghong in his doctoral thesis "Casing Damage Forecasting Method and Its Application in the process of Oilfield Development", combining with the geological data of oilfield and the main mechanism of casing damage, the vector machine method was used to establish the casing corrosion model of casing damage well, and a set of casing prediction software is designed to predict casing damage risk grade [9]. It provides suggestions for the production of oil and gas fields.

Through data analysis, the post-processing of the caliper data, whether it is the visual analysis of the test data or the improvement of the evaluation criteria, is based on the purpose of better evaluating the type and extent of the casing damage. However, the articles have not explicitly propose the classification of the type of casing damage, and provide appropriate workover techniques for the oilfield according to the type and classification of casing damage, maximizing cost savings and improving efficiency.

\section{Domestic casing damage casing classification method}

The classification of the damage degree of the casing damage well has not been successfully used in the oil field in China. The analysis of the casing damage well is still in the theoretical research stage. Dr. Sun Yudun from Central South University applied a method based on the equivalent MISES stress to the stress distribution around the casing in his doctoral thesis "Study on the casing damage mechanism and prevention measures of heavy oil thermal recovery wells in Gudong Oilfield". The level of casing damage is measured according to the amount of deformation of the casing under stress. In the paper, the classification of shear stress, compressive stress and tensile stress are proposed. Each type of damage is divided into four levels: absolute safety, safety, critical state and damage [10].

Among them, casing damage under shear stress is classified according to the deformation of casing under shear stress, casing damage under extrusion stress is classified according to the ratio of long axis to short axis after casing deformation, and casing damage under tensile stress is classified according to the percentage of casing wall thickness to wall thickness. Taking $339.7 \mathrm{~mm}$ casing as an example, the specific classification basis is shown in Table 1.

Table 1. Casing grading standard.

\begin{tabular}{|l|c|c|c|}
\hline $\begin{array}{c}\text { Classification of casing damage } \\
\text { by shear stress }\end{array}$ & $\begin{array}{c}\text { Classification of casing damage } \\
\text { grade by extrusion stress }\end{array}$ & $\begin{array}{c}\text { Classification of casing damage } \\
\text { grade under tensile stress }\end{array}$ \\
\hline
\end{tabular}




\begin{tabular}{|c|c|c|c|}
\hline Absolute safety & $\mathrm{A}<6 \mathrm{~mm}$ & $\mathrm{~B}<1.03$ & $\mathrm{C}<4 \%$ \\
\hline Safety & $6 \mathrm{~mm}<\mathrm{A}<12 \mathrm{~mm}$ & $\begin{array}{c}1.03<\mathrm{B}< \\
1.04\end{array}$ & $\begin{array}{c}4 \%<\mathrm{C}< \\
12.5 \%\end{array}$ \\
\hline Critical state & $\mathrm{A}=12 \mathrm{~mm}$ & $\mathrm{~B}=1.04$ & $\mathrm{C}=12.5 \%$ \\
\hline Damage & $\mathrm{A}>12 \mathrm{~mm}$ & $\mathrm{~B}>1.04$ & $\mathrm{C}>12.5 \%$ \\
\hline
\end{tabular}

Note: $\mathrm{A}$ in Table 1 shows the casing deformation, $\mathrm{B}$ shows the ratio of long axis to short axis, and $\mathrm{C}$ shows the percentage of casing wall thickness variation to casing wall thickness.

Weng Dongzi of the logging company of Sinopec Shengli Oilfield Engineering Co. Ltd. used ultrasonic imaging to measure casing inner and outer diameter damage and wall thickness damage in his article "Quantitative Classification Evaluation of Casing Damage by LOGIQ Acoustic Imaging Logging". The relative formula is used to comprehensively evaluate casing damage. In this paper, the inner diameter damage and outer diameter damage are summed up as casing thickness damage. The damage of wall thickness is divided into five grades, and different damage grades are expressed in different colors [11]. A case study is also given. Classification is shown in Table 2.

Domestic research on casing damage classification is at the theoretical stage, and the treatment of casing damage classification is not perfect[12-13]. However, the theoretical work done by scholars has a strong guiding significance for the classification of casing damage and the later repair work. By referring to the work of the above scholars, the theory of casing loss grading can be improved, and the establishment of expert system for maintenance evaluation of casing damage can be provided.
Table 2. Classification standard of casing wall thickness damage.

\begin{tabular}{|c|c|}
\hline $\begin{array}{c}\text { Grade and color } \\
\text { display }\end{array}$ & $\begin{array}{c}\text { Casing wall thickness damage } \\
\text { (D) }\end{array}$ \\
\hline 1 level (white) & $0<\mathrm{D}<20 \%$ \\
\hline 2 level (green) & $20 \%<\mathrm{D}<40 \%$ \\
\hline 3 level (yellow) & $40 \%<\mathrm{D}<60 \%$ \\
\hline 4 level (red) & $60 \%<\mathrm{D}<80 \%$ \\
\hline 5 level (black) & $80 \%<\mathrm{D}$ \\
\hline
\end{tabular}

\section{Casing maintenance evaluation expert system}

The purpose of the set of damage evaluation expert system is to comprehensively manage the casing damage data of oil and gas fields. With the help of the expert system, workover engineers can quickly and accurately understand the data to be repaired, such as the 3D model of the casing damage after 3D modeling, the rock formation properties of the well to be repaired, the workover records of the well to be repaired, etc. Wait. The main functions of the expert system are shown in Table 3.

Table 3. Casing well maintenance evaluation expert system function table.

\begin{tabular}{|c|c|}
\hline $\begin{array}{l}\text { The main } \\
\text { function }\end{array}$ & Function Description \\
\hline $\begin{array}{c}\text { Document } \\
\text { management }\end{array}$ & $\begin{array}{l}\text { Open the switch casing damage evaluation project file, create a new casing damage evaluation } \\
\text { project file, modify the project file information, delete the selected casing damage evaluation } \\
\text { project file, export the selected file as a disk file, and import an exported file into the software. }\end{array}$ \\
\hline $\begin{array}{l}\text { Nesting damage } \\
\text { evaluation }\end{array}$ & $\begin{array}{l}\text { Generate a three-dimensional model of the casing according to the opened file, determine the } \\
\text { type of casing damage, determine the damage level, and generate an evaluation report } \\
\text { according to the requirements of the user. }\end{array}$ \\
\hline Repair plan & $\begin{array}{l}\text { According to the type and level of casing damage, it can be repaired, judged to be repaired, the } \\
\text { corresponding repair tools and materials are given, the overall cost of the required tools and } \\
\text { materials can be calculated, and different sets of plans can be analyzed. Choose the most } \\
\text { economical solution, and generate an evaluation report based on user requirements. }\end{array}$ \\
\hline $\begin{array}{c}\text { System } \\
\text { Management }\end{array}$ & $\begin{array}{l}\text { Maintain account information of operating software, set software features, such as: whether to } \\
\text { display prompt help, etc., basic data of common casing damage, three-dimensional model, } \\
\text { commonly used repair tool parameters, customers can periodically upgrade software, the } \\
\text { upgrade process does not affect the original project Use of data }\end{array}$ \\
\hline
\end{tabular}


The casing damage evaluation expert system can greatly facilitate the management of casing damage wells in oil and gas fields. With the help of the system, the workover operation evaluation can minimize the influence of human factors. At the same time, the data management function of the system can make the oil and gas field timely understand the causes of the casing damage and predict the economic losses that may be caused by the casing damage. A reasonable workover plan is given according to the type and grade of casing damage, workover tools, current oil price, and estimated production after repair.

\section{Conclusion}

This paper analyzes and summarizes the typical casing damage forms of casing. Combining with the application of caliper in casing damage detection and the post-processing of testing data, this paper analyzes the present situation of caliper detection and points out that the current caliper detection and post-processing cannot classify casing damage and provide reasonable workover technology for oil and gas fields.

The fact that combined with the generation of damaged wells will bring huge economic losses to the oil and gas fields every year. The current research status of the current casing loss classification is analyzed, and the advantages of the work done by relevant scholars are pointed out. Combining the research and theoretical advantages of scholars, the concept of the expert system for the evaluation of the damage prevention well is proposed. Through the analysis of the whole workover process, each step is refined and the cost is calculated, combined with casing damage. The degree and grade, current oil price, and estimated production after oil and gas well restoration are used to evaluate the economics of casing damage repair. In combination with the evaluation criteria, suggestions for restoration such as scrapping treatment, diseased production, and discontinuation of production are proposed.

The maintenance evaluation of casing damage well is of great help to the solution of oil and gas well casing damage. By establishing the expert system of casing damage classification evaluation, the whole evaluation process is quantified, and the interference of human factors on the evaluation results is greatly reduced, so that the evaluation results are more credible. At the same time, the entire process of repairing the damaged well is also standardized. The establishment of the expert system for the classification and maintenance evaluation of the damaged wells is of great significance for the oil and gas field standardized workover operation process, the economic evaluation of the casing damage repair, and the improvement of production efficiency.

\section{References}

1. Peng, S.P., Fu, J.T.\&Zhang, J.C. Borehole casing failure analysis in unconsolidated formations: A case study. Journal of Petroleum Science and Engineering, 59, 226-238(2007).
2. Zhao, Z.F. Dynamic Safety Evaluation Method for the Long-distance Pipeline Corrosion Protection System. Xi'an University of Science and Technology(2017).

3. Que, Y. Comprehensive treatment of casing damage wells to ensure sustainable development of Daqing Oilfield. China University of Geosciences(2009).

4. Zhou, Z., He, J.P.\&Huang, M.H. Casing Pipe Damage Detection with Optical Fiber Sensors: A Case Study in Oil Well Constructions. Hindawi Publishing Corporation: Advances in Civil Engineering(2010).

5. Qi, W.J. The Research and Implementation of 3-D Imaging System for Multi-arm caliper logging tool. Electronic Test, 2, 85-86(2014).

6. Liu, L. The study and realization of the system of the casing $3 \mathrm{D}$ visualization and casing damage identification. Northeast Petroleum University(2014).

7. Zhang, N.N. Research on Casing Damage Multi-arm Caliper Detection Technology. Xi'an Petroleum University(2015).

8. Xiao, Y. Study on the Mechanism、Inspection and Prediction of Casing Damage. DaQing Petroleum Institute(2007).

9. Jia, J, H. Casing damage forecasting method and its application in the process of oilfield development. China University of Petroleum(2009).

10. Sun, S.D. Study on Mechanism of and Prevention and Control Measures Against Casing Failure of Heavy Oil Thermal Recovery Wells in Gudong Oil Field. Central South University(2010).

11. Weng, D.Z. Quantitative evaluation of casing damage using LOGIQ acoustic imaging logs. The 9th Annual Youth Academic Conference of China Petroleum Institute(2015).

12. AI, C., LIU, Y.Z. \& LI,Y.W. Evaluating Casing Damage Basing on Fuzzy Comprehensive Evaluation and Grey Relational Grade Analysis. Petroleum Exploration and Development, 8, 43-47(2014).

13. Yang, B. Research on Casing Repair Technology for Casing Damage Wells. China University of Petroleum(2007). 